University of Nebraska - Lincoln

DigitalCommons@University of Nebraska - Lincoln

USDA National Wildlife Research Center - Staff Publications
U.S. Department of Agriculture: Animal and Plant Health Inspection Service

2011

\title{
White-Tailed Deer Incidents With U.S. Civil Aircraft
}

Kirsten M. Biondi

Carnivore Ecology Laboratory, Forest and Wildlife Research Center, Mississippi State University

Jerrold L. Belant

Carnivore Ecology Laboratory, Forest and Wildlife Research Center, Mississippi State University

James A. Martin

Agricultural Ecology and Carnivore Ecology Labs, Forest and Wildlife Research Center, Mississippi State University

Travis L. Devault

USDA/APHIS/WS National Wildlife Research Center, Travis.L.DeVault@aphis.usda.gov

Guiming Wang

Department of Wildlife, Fisheries, and Aquaculture, Mississippi State University

Follow this and additional works at: https://digitalcommons.unl.edu/icwdm_usdanwrc

Part of the Environmental Sciences Commons, and the Life Sciences Commons

Biondi, Kirsten M.; Belant, Jerrold L.; Martin, James A.; Devault, Travis L.; and Wang, Guiming, "WhiteTailed Deer Incidents With U.S. Civil Aircraft" (2011). USDA National Wildlife Research Center - Staff Publications. 1008.

https://digitalcommons.unl.edu/icwdm_usdanwrc/1008

This Article is brought to you for free and open access by the U.S. Department of Agriculture: Animal and Plant Health Inspection Service at DigitalCommons@University of Nebraska - Lincoln. It has been accepted for inclusion in USDA National Wildlife Research Center - Staff Publications by an authorized administrator of DigitalCommons@University of Nebraska - Lincoln. 
Original Article

\title{
White-Tailed Deer Incidents With U.S. Civil Aircraft
}

\author{
KRISTIN M. BIONDI, ${ }^{\mathbf{1}}$ Carnivore Ecology Laboratory, Forest and Wildife Research Center, Mississippi State University, Mississippi State, \\ MS 39762, USA \\ JERROLD L. BELANT, Carnivore Ecology Laboratory, Forest and Wildife Research Center, Mississippi State University, Mississippi State, \\ MS 39762, USA \\ JAMES A. MARTIN, Agricultural Ecology and Carnivore Ecology Labs, Forest and Wildlife Research Center, Mississippi State University, \\ Mississippi State, MS 39762, USA \\ TRAVIS L. DEVAULT, United States Department of Agriculture, Animal and Plant Health Inspection Service, Wildife Services, \\ National Wildlife Research Center, Obio Field Station, 6100 Columbus Avenue, Sandusky, OH 44870, USA \\ GUIMING WANG, Department of Wildlife, Fisheries, and Aquaculture, Mississippi State University, Mississippi State, MS 39762, USA
}

\begin{abstract}
Aircraft incidents with ungulates cause substantial economic losses and pose risks to human safety. We analyzed 879 white-tailed deer (Odocoileus virginianus) incidents with United States civil aircraft from 1990 to 2009 reported in the Federal Aviation Administration National Wildlife Strike Database. During that time, deer incidents followed a quadratic response curve, peaking in 1994 and declining thereafter. There appeared to be some seasonal patterning in incident frequency, with deer incidents increasing overall from January to November, and peaking in October and November (30.7\%). Most incidents $(64.8 \%)$ occurred at night, but incident rates were greatest $(P \leq 0.001)$ at dusk. Landing-roll represented $60.7 \%$ of incidents and more incidents occurred during landing than take-off $(P \leq 0.001)$. Almost $70 \%$ of deer incidents had an effect on flight. About $6 \%$ of pilots attempted to avoid deer, and were less likely to sustain damage. Aircraft were 25 times more likely to be destroyed when multiple deer were struck versus a single individual. Deer incidents represented $0.9 \%$ of all wildlife incidents, yet $5.4 \%$ of total estimated costs. Reported costs for deer incident damages during this period exceeded US $\$ 36$ million, with US $\$ 75$ million in total estimated damages. Deer incidents resulted in 1 of 24 human deaths and 26 of 217 injuries reported for all wildlife incidents with aircraft during the reporting period. Managers should implement exclusion techniques (e.g., fences, cattle guards, or electrified mats) to maximize reductions in deer use of airfields. Where exclusion is not practical, managers should consider lethal control, habitat modifications, increased monitoring and hazing, and improved technology to aircraft and runway lighting to reduce incidents at airports. (c) 2011 The Wildlife Society.
\end{abstract}

KEY WORDS airport, airport management, aviation hazard, Odocoileus virginianus, white-tailed deer, wildlife-aircraft incident, wildlife strike.

White-tailed deer (Odocoileus virginianus) are the most widely distributed and abundant ungulate in North America (Miller et al. 2010) and occur in 45 of the contiguous United States (U.S.; Miller et al. 2003). White-tailed deer densities are 2-4 times higher than historical densities and deer are considered overabundant in most areas of eastern North America (Knight et al. 2009). Overabundance of deer has led to a concomitant increase in human-wildlife conflicts, including agricultural damage (Conover and Decker 1991, Tzilkowski et al. 2002), forest damage (Rooney et al. 2002, Horsley et al. 2003), potential disease threats (Conover 2002, Telford 2002, Côté et al. 2004), herbivory pressure to native plant communities (Knight et al. 2009), and vehicle collisions (Conover et al. 1995, Bissonette et al. 2008,

Received: 9 December 2010; Accepted: 9 June 2011

${ }^{1}$ E-mail: kbiondi@cfr.msstate.edu
DeNicola and Williams 2008, Gosner et al. 2009). These conflicts result in >US\$2 billion in economic losses (see Conover 1997, Bissonette et al. 2008, DeNicola and Williams 2008) and hundreds of human deaths (Bissonette et al. 2008, DeNicola and Williams 2008, Gosner et al. 2009) annually.

There are an estimated $>1$ million deer (Odocoileus spp.) collisions with automobiles annually (Conover et al. 1995, DeNicola and Williams 2008), but automobiles are not the only vehicles that collide with deer. Though far less frequent, deer collisions with aircraft pose a real danger to the aviation industry (Wright et al. 1998, Dolbeer et al. 2000). Deer are ranked the most hazardous wildlife to U.S. civil aircraft (Dolbeer et al. 2000, Dolbeer and Wright 2009). Most airports contain open fields with nearby grasslands and wooded areas (Wright et al. 1998), and many have adjacent agricultural crops such as corn and soybeans (Blackwell et al. 2009, DeVault et al. 2009); therefore, they are highly 
attractive to deer. Deer collisions with aircraft have been reported every year since 1983 and often result in substantial damage (Wright et al. 1998). White-tailed deer represented 93\% of ungulate incidents with U.S. civil aircraft from 1983 to 1997 (Wright et al. 1998).

Wright et al. (1998) summarized 343 reported ungulate incidents with aircraft during 1983-1997. Our objective was to update the synthesis of Wright et al. (1998) specific to white-tailed deer because they were the most common mammal species involved in incidents with aircraft. We examined spatial and temporal characteristics of white-tailed deer incidents with U.S. civil aircraft (hereafter, deer incidents) and the outcomes of these incidents, and provided ecological and behavioral theoretical support to explain observed patterns in incidents.

\section{METHODS}

We searched the Federal Aviation Administration (FAA) National Wildlife Strike Database containing data from 1990 to 2009 for reported incidents involving white-tailed deer and U.S. civil aircraft. This database was derived from information voluntarily reported to the FAA by pilots and airports using FAA Form 5200-7 (Dolbeer et al. 2009). Many reports were incomplete and not included for some analyses; therefore, sample sizes varied among variables.

We summarized the number of deer incidents reported annually and calculated annual deer incident rates/1 million U.S. civil aircraft operations using the FAA Terminal Area Forecast Summary Report FY 2009-2030 (FAA 2010a). The 2009 aircraft flight data were provided as estimates because the database was updated before the end of 2009. We summarized the number of deer incidents reported monthly and calculated deer incident rates/1 million U.S. civil aircraft operations using the FAA Air Traffic Activity System (FAA 2010b). However, monthly operations from 1990 were not included in the database and, therefore, not calculated in the incident rates. We also calculated the number of incidents/hr by time of day, as categorized in the FAA Wildlife Strike Database. Dawn and dusk represented $0.75 \mathrm{hr}$ each, whereas night and day represented $11.25 \mathrm{hr}$ each (after Wright et al. 1998). We summarized the number of incidents by state and used geographic range of white-tailed deer provided by Miller et al. (2003).

To assess frequency of deer incidents by aircraft phase of flight, we defined approach as an aircraft engaged in landing with at least one wheel off the ground. Climb was defined as an aircraft engaged in take-off with at least one wheel off the ground. Taxi was an aircraft moving between the gate and the runway. Because taxi occurs twice during each flight, before take-off and after landing, percent of incidents during taxi was reduced by half to standardize incidents by movement type. An aircraft was classified in landing roll or takeoff run when all wheels were on the ground during landing and take-off, respectively (Dolbeer and Wright 2009). We defined landing as the combination of approach and landingroll, and take-off as the combination of climb and take-off run. We summarized aircraft components (e.g., engine, wing or rotor, other) damaged in incidents as reported in the FAA National Wildlife Strike Database.

We categorized incidents as involving a single or multiple $(>1)$ deer. We defined avoidance incidents when aircraft engaged in maneuvers in an attempt to avoid deer, even if the deer was struck. We used the FAA Airport Facilities Data Report (FAA 2010c) to compare frequency of deer incidents between certificated and noncertificated airports within the National Plans of Integrated Airport Systems. This report includes all airports that are eligible for federal funding and submit FAA Form 5200-7 (FAA 2010c).

We used damage classes (none, minor, substantial, and destroyed) from the FAA Wildlife Strike Database to assess the amount of damage incurred (Dolbeer et al. 2009). None were defined as no damage occurred. Minor damage could be fixed by simple repairs or replacement of parts and extensive inspection was not necessary. Substantial damage affected structural strength, performance, or flight characteristics, and the aircraft required major repair or replacement of parts. Destroyed damage included aircraft that could not be restored to airworthy condition. All forms of damage were combined to make an overall damage category termed any damage. We summarized effect on flight and aircraft out of service as provided by the FAA National Wildlife Strike Database. Effect on flight was any deviation from a normal flight routine (e.g., aborted take-off or landing, delayed flight). An aircraft was considered out of service when not in use while undergoing repairs.

We estimated total cost of damage for white-tailed deer incidents by averaging reported costs for each damage class, multiplying these averages by the total number of incidents within each respective damage class, and summing all estimates. For comparison, we similarly calculated estimated total cost of damage for all other reported wildlife incidents. Cost values were taken from FAA National Wildlife Strike Database and were adjusted for inflation to 2010 using the Consumer Price Index.

We used regression techniques $(\alpha=0.05)$ to assess trends in incident rates across years and Chi-square analyses to compare the number of incidents among months, phase of flight, and incident rates/hour by time of day (e.g., day, night). We used multinomial logistic regression to assess the effects of aircraft body mass, number of deer involved in incidents ( 1 or $>1$ ), and phase of flight on aircraft damage class. We ran all combinations of variables including a null model for a total of 7 candidate models. Akaike Information Criterion (AIC) was used to rank models based on model complexity and fit (Burnham and Anderson 2002). We used model-averaged parameter estimates to assess the direction and magnitude of deer incident effects on aircraft damage. Means are reported with +1 standard deviation (SD), 95\% confidence intervals $(\mathrm{CI})$, or odds ratios $(\mathrm{OR})$.

\section{RESULTS}

\section{Characteristics of Incidents}

From 1990 to 2009, 879 incidents involving deer and U.S. civil aircraft were reported, averaging 44 incidents/year 


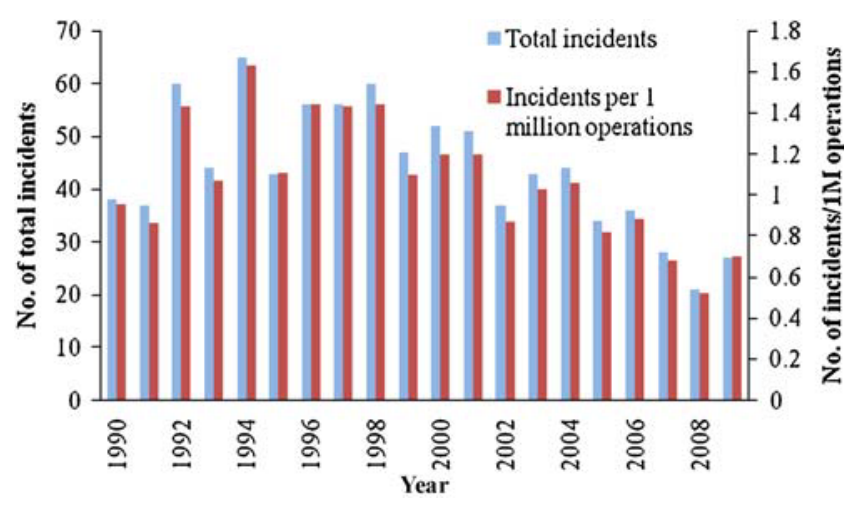

Figure 1. Number and standardized rate of white-tailed deer (Odocoileus virginianus) incidents $(n=879)$ with U.S. civil aircraft by year, 1990-2009.

$(\mathrm{SD}=12$, range $=21-65)$ (Fig. 1). The greatest incident rate occurred in 1994, with 1.63 incidents/1 million operations. Overall, annual incident rates $/ 1$ million operations increased $\left(y=-9.12+9.13 x-2.29 x^{2}\right.$; adjusted $\left.r^{2}=0.65, P \leq 0.001\right)$ through 1994 , then declined.

Incidents occurred in 39 of 45 states within the geographic range of white-tailed deer in the United States. Of deer incidents reported by state $(n=873), 78.1 \%$ occurred east of the Mississippi River. States with the greatest number of incidents from 1990 to 2009 included Michigan $(n=77)$, New York $(n=68)$, Pennsylvania $(n=66)$, and West Virginia $(n=54)$. Four states reported one incident each and 6 states reported no incidents.

Number of deer incidents varied $\left(n=879 ; \chi_{11}^{2}=199.51\right.$, $P \leq 0.001$ ) across months (Fig. 2). Deer incidents and incident rates increased overall from January to November. October and November accounted for $30.7 \%$ of all reported deer incidents. Deer incidents decreased $64.7 \%$ in December compared to November and remained low ( $<50$ strikes/ month) through May. Incident rates followed about the same pattern as number of incidents.

Most (64.8\%) incidents occurred at night, followed by day (Fig. 3). However, the highest $\left(\chi_{3}^{2}=168.13, P \leq 0.001\right)$ incident rate occurred during dusk, followed by night. Daytime had the second-most total incidents (20.8\%) but had the lowest incident rate. The percentage of deer

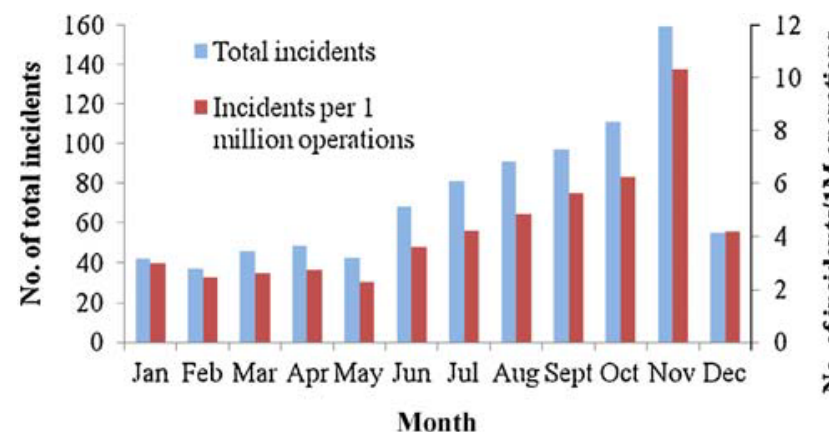

Figure 2. Number (1990-2009) and standardized rate (1991-2009) of white-tailed deer (Odocoileus virginianus) incidents $(n=879)$ with U.S. civil aircraft by month.

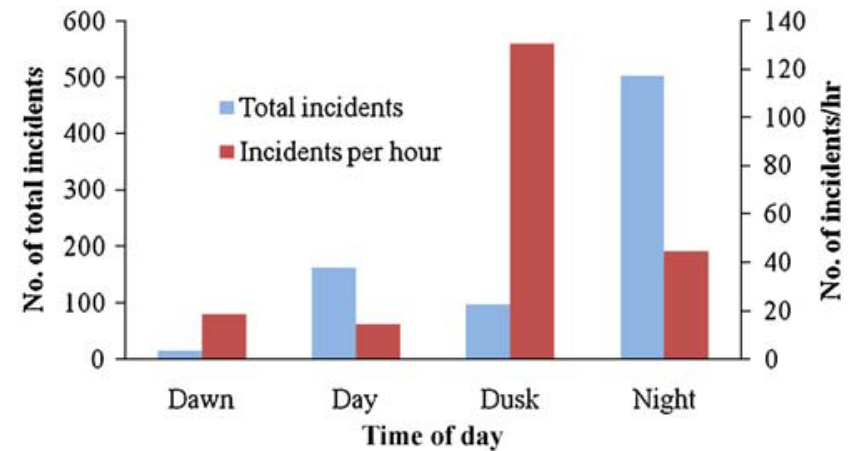

Figure 3. Number $(n=778)$ and rate (incidents/hr) of white-tailed deer (Odocoileus virginianus) incidents with U.S. civil aircraft by time of day, 1990-2009.

incidents at night increased from June through December before decreasing again through June (Fig. 4).

Most incidents occurred when aircraft were in landing-roll, followed by take-off run (Fig. 5). More $\left(\chi_{2}^{2}=574.64\right.$, $P \leq 0.001)$ incidents occurred during landing (68.6\%) than take-off (29.4\%) or taxi (2.0\%). Parts of the aircraft reported struck $(n=1,345)$ most often were landing gear (25.9\%), propeller (15.8\%), other (15.5\%), and wing or rotor (14.6\%). Landing gear was damaged in $86.8 \%$ of reported incidents and propellers were damaged in $94.8 \%$ of reported incidents in which those aircraft parts were struck.

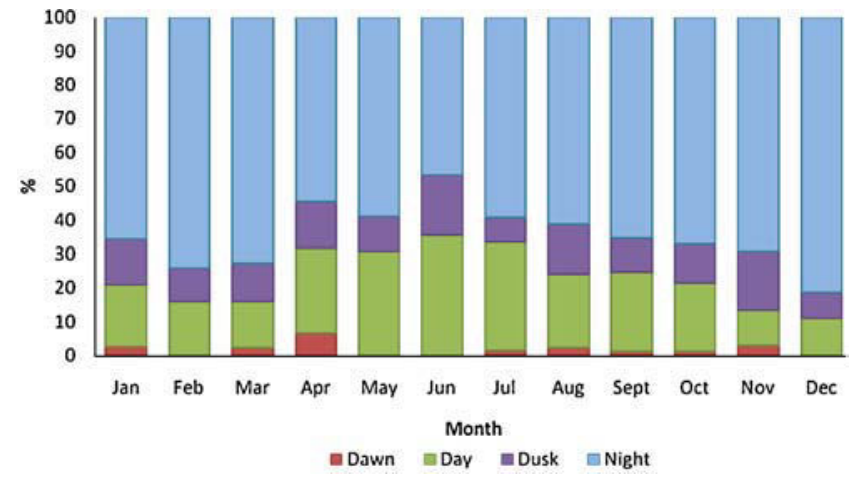

Figure 4. Percent of white-tailed deer (Odocoileus virginianus) incidents $(n=778)$ with U.S. civil aircraft by month and time of day, 1990-2009.



Figure 5. Percent (+95\% CI) of white-tailed deer (Odocoileus virginianus) incidents $(n=854)$ with U.S. civil aircraft by aircraft movement, 19902009. 


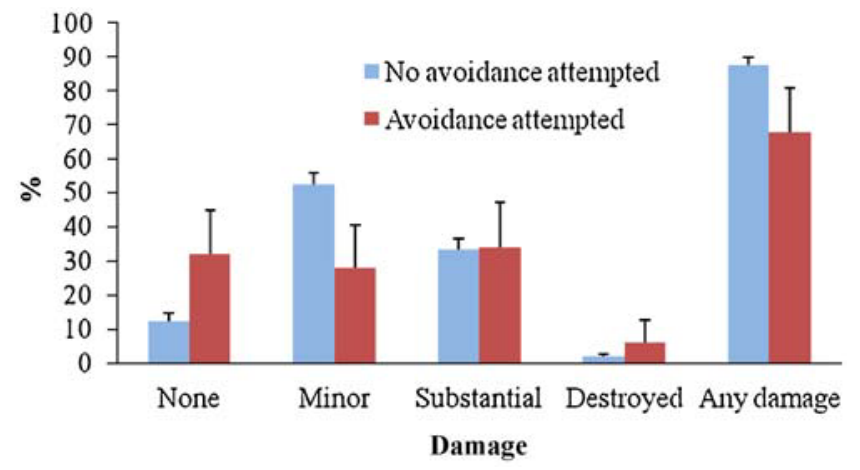

Figure 6. Percent damage ( $+95 \%$ CI) of U.S. civil aircraft taking measures to avoid $(n=50)$ or not avoid $(n=800)$ collisions with white-tailed deer (Odocoileus virginianus), 1990-2009.

When a pilot reported seeing multiple deer during an incident $(n=161), 45 \%$ reported striking $>1$ deer. Pilots that reported attempting to avoid deer represented $5.9 \%$ of total incidents $(n=879)$; however, this does not reflect the number of incidents in which deer were avoided because not all avoidance attempts were successful. Aircraft attempting to avoid deer $(n=50)$ were less likely to sustain damage (Fig. 6); however, of 18 aircraft reported destroyed, 3 occurred while attempting to avoid deer. More deer incidents $(n=868)$ occurred at noncertificated airports (64.1\%) than certificated airports (35.9\%). Of certificated airports $(n=585), 53.3 \%$ reported $\geq 1$ deer incident. In contrast, only $20.2 \%$ of noncertificated airports $(n=2,753)$ reported $\geq 1$ deer incident.

\section{Effects of Incidents}

In multinomial logistic regression analyses, the global model garnered most Akaike weight $\left(\omega_{i}=0.89\right.$; Table 1$)$ and was 8 times more likely to be the best approximating model than the second-ranked model. Model weight (0.11) for the nextbest model included number of deer involved in incidents (Deer_Struck) and aircraft mass (AC_Mass); weights of remaining models were $<0.01$.

Given the exploratory nature of our modeling, we averaged parameter estimates across all models. Aircraft were 3.5 times more likely to be destroyed during the take-off phase of flight (Table 2). Likelihood of other damage classes were not affected (CLs included zero) by phase of flight. Aircraft incidents with multiple deer increased the likelihood of damage for all classes. Most strikingly, aircraft were 25 times $(1 / 0.04=25)$ more likely to be destroyed when multiple deer were struck versus a single animal. In general, as aircraft mass (AC_Mass) increased, the likelihood of greater damage decreased. For example, aircraft weighing 5,701-27,000 kg were about 11 times less likely to be destroyed than aircraft weighing $<2,250 \mathrm{~kg}$.

Deer incidents were more likely to result in damage to aircraft than other wildlife incidents (Table 3). For example, deer incidents represented $32.7 \%$ of aircraft destroyed by all wildlife incidents $(n=55)$. Of deer incidents that included

Table 1. Multinomial logistic-regression model-fitting results for damage sustained by U.S. civil aircraft from incidents with white-tailed deer (Odocoileus virginianus), 1990-2009. Models are compared using number of parameters (K), Akaike's Information Criterion (AIC), the difference in AIC from best-fitting model $(\Delta \mathrm{AIC})$, and model weight $(\omega)$.

\begin{tabular}{|c|c|c|c|c|}
\hline Model $^{\mathbf{a}}$ & $K$ & AIC & $\Delta \mathrm{AIC}$ & $\omega$ \\
\hline Deer_Struck, Flight_Phase, AC_Mass & 7 & $1,420.0$ & 0.0 & 0.89 \\
\hline Deer_Struck, AC_Mass & 6 & $1,424.3$ & 4.3 & 0.11 \\
\hline Flight_Phase, AC_Mass & 6 & $1,430.5$ & 10.5 & $<0.01$ \\
\hline AC_Mass & 5 & $1,434.4$ & 14.4 & $<0.01$ \\
\hline Deer_Struck, Flight_Phase & 4 & $1,504.8$ & 84.8 & $<0.01$ \\
\hline Deer_Struck & 3 & $1,509.9$ & 89.9 & $<0.01$ \\
\hline Flight_Phase & 3 & $1,513.8$ & 93.8 & $<0.01$ \\
\hline Null & 2 & $1,518.5$ & 98.5 & $<0.01$ \\
\hline
\end{tabular}

${ }^{a}$ Model terms are number (1 or $>1$ ) of deer struck (Deer_Struck), aircraft mass (AC_Mass), and phase of flight (landing or takeoff; Flight_Phase). Aircraft mass was categorized as $1=\leq 2,250 \mathrm{~kg}, 2=2,251-5,700 \mathrm{~kg}, 3=5,701-27,000 \mathrm{~kg}$, or $4=27,001-272,000 \mathrm{~kg}$.

Table 2. Multinomial logistic-regression model parameter estimates, 95\% lower (LCL) and upper (UCL) confidence limits, and odds ratios (OR) for damage class sustained by U.S. civil aircraft from incidents with white-tailed deer (Odocoileus virginianus), 1990-2009. Reference factors for explanatory variables are: Phase-Approach, Deer Struck-Multiple, and AC_Mass-1.

\begin{tabular}{|c|c|c|c|c|c|c|c|c|c|c|c|c|}
\hline \multirow[b]{3}{*}{ Parameter $^{\mathbf{b}}$} & \multicolumn{12}{|c|}{ Damage class $^{a}$} \\
\hline & \multicolumn{4}{|c|}{ Minor } & \multicolumn{4}{|c|}{ Substantial } & \multicolumn{4}{|c|}{ Destroyed } \\
\hline & $\beta$ & LCL & UCL & $\overline{\mathrm{OR}}$ & $\beta$ & LCL & UCL & $\overline{\mathrm{OR}}$ & $\beta$ & LCL & UCL & OR \\
\hline Intercept & 3.45 & 1.91 & 4.99 & & 3.69 & 2.12 & 5.26 & & 1.63 & -0.41 & 3.66 & \\
\hline Phase-Take-off & -0.33 & -0.86 & 0.19 & 0.72 & -0.06 & -0.62 & 0.50 & 0.94 & 1.26 & 0.10 & 2.42 & 3.53 \\
\hline Deer_Struck-Single & -1.48 & -2.97 & 0.00 & 0.23 & -2.01 & -3.51 & -0.51 & 0.13 & -3.20 & -5.09 & -1.30 & 0.04 \\
\hline AC_Mass-2 & -0.31 & -1.01 & 0.40 & 0.73 & -0.24 & -0.96 & 0.48 & 0.79 & -0.83 & -2.21 & 0.54 & 0.44 \\
\hline AC_Mass-3 & -0.54 & -1.20 & 0.12 & 0.58 & -1.22 & -1.93 & -0.51 & 0.30 & -2.37 & -4.54 & -0.20 & 0.09 \\
\hline
\end{tabular}

${ }^{a}$ Damage class was the response variable, which included 4 factors: None (reference category), Minor, Substantial, and Destroyed.

${ }^{\mathrm{b}}$ Model terms are number (1 or $>1$ ) of deer struck (Deer_Struck), aircraft mass (AC_Mass), and phase of flight (landing or take-off; Flight_Phase). Aircraft mass was categorized as $1=\leq 2,250 \mathrm{~kg}, 2=2,251-5,700 \mathrm{~kg}, 3=5,701-27,000 \mathrm{~kg}$, or $4=27,001-272,000 \mathrm{~kg}$. 
Table 3. Percent and sample size of white-tailed deer (Odocoileus virginianus) and other wildlife incidents with U.S. civil aircraft by damage type, $1990-2009$.

\begin{tabular}{|c|c|c|c|c|}
\hline \multirow[b]{2}{*}{ Damage type $^{a}$} & \multicolumn{2}{|c|}{ White-tailed deer } & \multicolumn{2}{|c|}{ Other wildlife } \\
\hline & $n$ & $\%$ & $n$ & $\%$ \\
\hline Damage occurred & 850 & 86.5 & 75,639 & 13.7 \\
\hline Substantial or destroyed & 850 & 35.4 & 75,639 & 3.5 \\
\hline Aircraft out of service $\geq 1$ month & 214 & 44.9 & 4,857 & 3.3 \\
\hline
\end{tabular}

${ }^{\text {a }}$ Damage occurred represents aircraft sustaining any category of damage (minor, substantial, or destroyed) and aircraft out of service is any aircraft not operational while undergoing repairs.

an effect on aircraft $(n=575), 69.7 \%$ had some effect on flight. Aircraft were out of service for $\geq 1$ month more frequently from deer incidents than other wildlife incidents. Reported total time out of service $(n=214)$ for deer incidents was 204,986 hr or 23.4 years during the 20-year period examined.

Deer incidents represented $0.9 \%$ of all wildlife incidents, yet $5.4 \%$ of total estimated costs $(n=99,415)$. Total reported cost for any damage $(n=246)$ by deer exceeded US \$36 million, although we estimated cost for all incidents reporting any damage $(n=735)$ to be US $\$ 75$ million. Total reported cost for any damage by all wildlife $(n=2,721)$ was US $\$ 463$ million, with about US $\$ 1.4$ billion estimated total cost.

Deer incidents resulted in 1 of 24 human deaths and 26 of 217 injuries reported for all wildlife incidents with aircraft during the reporting period. The single death resulted from an infection due to an injury sustained from the incident. Injuries ranged from minor to critical, including burns, fractures, and broken bones. Human injuries from deer incidents occurred only when aircraft incurred substantial damage or were destroyed.

\section{DISCUSSION}

Large mammals, especially ungulates, are considered the most hazardous wildlife to aircraft (Wright et al. 1998, Dolbeer and Wright 2009). Similarly, Dolbeer et al. (2000) ranked deer as having the highest relative hazard score of all wildlife. The general trend for deer-aircraft incidents has declined since 1994. Interestingly, this trend is opposite national deer population trends for the same period (Miller et al. 2003). However, deer-vehicle collisions have increased with increasing deer populations (Hussain et al. 2007), suggesting a positive effect of deer management at airports. However, a cause-and-effect relationship cannot be assumed because of the correlative nature of our findings. Information in the FAA National Wildlife Strike Database did not allow for more thorough analysis on causative factors for the decline in deer-aircraft incidents.

We found deer incidents, on average, resulted in 6 times greater economic damage to aircraft than strikes with other wildlife. Furthermore, extent of damage increased in incidents involving multiple deer. Relative hazards of wildlife to aircraft increases with body mass (Dolbeer et al. 2000) and number of individuals colliding with aircraft (T. L. DeVault, in press). Deer incidents were not requested to be reported on Form 5200-7 until 1991 and only 39\% of all wildlife incidents may be reported at certified airports and fewer at general aviation airports (Dolbeer 2009); therefore, estimated aircraft damage and associated costs from deer incidents are likely conservative and underrepresented in the FAA National Wildlife Strike Database.

The high incident rates with aircraft during October and November corresponds with the deer breeding season (Conover 2002). Reduced vigilance of deer engaged in breeding behavior during rut (Iverson and Iverson 1999) may increase the likelihood of incidents with aircraft. Lower reported incident rates from December to February may result from deer use of areas with greater thermal cover and reduced spatial movement, especially in northern portions of their range (Pauley et al. 1993). Percent of deer incidents with aircraft by time of day generally followed changes in day length across months. White-tailed deer are typically crepuscular or nocturnal (Miller et al. 2003), corresponding with the higher rate of incidents during dusk and night. Increased deer activity during times of reduced pilot visibility may also explain, in part, the higher reported rate of incidents during these periods.

The higher rate of deer incidents during landing may be a consequence of several factors, including aircraft speed, relative visibility of deer, and deer and pilot behavior. Greater aircraft speed and pilot activity during landing would reduce ability to detect deer and reaction time, especially at night. Also, opportunities to avoid deer are greatly reduced during landing because of less favorable alternatives for the pilot. Predator avoidance behavior of deer may increase incident risk with aircraft. Adult deer lack aerial predators and rapidly habituate to loud noises or activities (Bomford and O'Brien 1990, Belant et al. 1996); consequently, deer may not initially perceive aircraft as a threat. The engine power reduction during landing may make aircraft less perceptible by deer due to the reduced engine noise (Wright et al. 1998). Pilots and deer would more likely detect each other during taxi and take-off; furthermore, evasive action by aircraft might be possible during these phases of flight.

Because of the high relative hazard of deer, we recommend managers implement programs that maximize reduction of deer use of airfields. Fences have been demonstrated to exclude deer from airports (Seamans and VerCauteren 2006, DeVault et al. 2008). To maximize efficacy, fences should be $\geq 2.4 \mathrm{~m}$ high (Cleary and Dolbeer 1999; VerCauteren et al. 2006, 2010), with no holes that would allow animals to pass through and with additional fence buried below ground (Cleary and Dolbeer 1999, DeVault 
et al. 2008). Similarly, the FAA recommends fences 3.0$3.7 \mathrm{~m}$ high (10-12 feet; FAA 2004). Fences must be properly maintained to ensure effectiveness (DeVault et al. 2008). If optimal fencing (e.g., 2.4-m-high woven wire) is impractical, less expensive fences are available (Seamans and VerCauteren 2006) but generally less effective. Installing deer or cattle guards (Belant et al. 1998, Cleary and Dolbeer 1999) or electrified mats (Seamans and Helon 2008) at entrances and other permanent openings will further reduce deer access to airfields. The comparatively high number of deer incidents at noncertificated (general aviation) airports may reflect those airports having less funding available for implementing deer exclusion or other techniques (e.g., DeVault et al. 2008, Dolbeer et al. 2008). General aviation airports with incomplete or no fencing had 15 times greater deer use than airports with complete fencing (DeVault et al. 2008).

Removal techniques can augment exclusion techniques. Sharpshooting is preferable to relocation because of high mortality rate and cost (Ishmael and Rongstad, 1984, O'Bryan and McCullough 1985, Jones and Witham 1990, Conover 2002, DeNicola and Williams 2008), and because of potential disease transmission (DeNicola and Williams 2008); however, removal will not be effective if proper exclusion is not incorporated. Where exclusion techniques are not used, harassment of deer using loud noises and flashing lights should be used sparingly to keep deer from runways (Craven and Hygnstrom 1994) before take-offs and landings. Sound deterrents operating at $4-8 \mathrm{kHz}$ are most effective (D'Angelo et al. 2007). However, deer may be deterred with sounds from $20 \mathrm{kHz}$ to $30 \mathrm{kHz}$, above human hearing, which would reduce negative experiences for airport personnel and travelers (D'Angelo et al. 2007). Increasing deer visibility by installing additional or unconventional lighting should also be considered. During low ambient light, deer apparently see blue to blue-green wavelengths (Yokoyama and Radlwimmer 1998, VerCauteren and Pipas 2003). Blackwell and Seamans (2009) demonstrated tungsten-halogen lights and Xenarc high-intensity discharge lamps increase the distance at which deer detect approaching vehicles. Additional research is warranted to develop new technology in the realm of lighting and sound to deter deer and other mammals.

\section{MANAGEMENT IMPLICATIONS}

We recommend airport managers prioritize reductions in deer and other large mammal use of airfields. Exclusion techniques have been demonstrated as most effective; however, other techniques are available when exclusion is impractical. Monitoring deer activity at airports should be implemented to determine peak deer use and maximize efficacy of control measures. Modifying habitat suitability, including reductions in food availability or palatability, as well as areas providing cover, should reduce deer use of airfields. Integration of control techniques will maximize reductions in deer use of airfields and consequent incidents with aircraft.

\section{ACKNOWLEDGMENTS}

Our work was supported by Mississippi State University, the United States Department of Agriculture, and the Federal Aviation Administration under agreement DTFACT-04X-90003. We thank B. F. Blackwell, T. W. Seamans, and M. J. Begier for reviewing drafts of this manuscript. Opinions expressed in this study do not necessarily reflect current Federal Aviation Administration policy decisions regarding the control of wildlife on or near airports.

\section{LITERATURE CITED}

Belant, J. L., T. W. Seamans, and C. P. Dwyer. 1996. Evaluation of propane exploders as white-tailed deer deterrents. Crop Protection 15:575-578.

Belant, J. L., T. W. Seamans, and C. P. Dwyer. 1998. Cattle guards reduce white-tailed deer crossings through fence openings. International Journal of Pest Management 44:247-249.

Bissonette, J., C. A. Kassar, and L. J. Cook. 2008. Assessment of costs associated with deer-vehicle collisions: human death and injury, vehicle damage, and deer loss. Human-Wildlife Conflicts 2:17-27.

Blackwell, B. F., T. L. DeVault, E. Fernández-Juricic, and R. A. Dolbeer. 2009. Wildlife collisions with aircraft: a missing component of land-use planning for airports. Landscape and Urban Planning 93:1-9.

Blackwell, B. F., and T. W. Seamans. 2009. Enhancing the perceived threat of vehicle approach to white-tailed deer. Journal of Wildlife Management 73:128-135.

Bomford, M., and P. H. O'Brien. 1990. Sonic deterrents in animal damage control: a review of device tests and effectiveness. Wildlife Society Bulletin 18:411-422.

Burnham, K. P., and D. R. Anderson. 2002. Model selection and multimodel inference. Second edition. Springer-Verlag, New York, New York, USA.

Cleary, E. C., and R. A. Dolbeer. 1999. Wildlife hazard management at airports, a manual for airport personnel. U.S. Department of Transportation, Federal Aviation Administration, Office of Airport Safety and Standards, Washington, D.C., USA.

Conover, M. R. 1997. Monetary and intangible valuation of deer in the United States. Wildlife Society Bulletin 25:298-305.

Conover, M. R. 2002. Resolving human-wildlife conflicts: the science of wildlife damage management. Lewis, Boca Raton, Florida, USA.

Conover, M. R., and D. J. Decker. 1991. Wildlife damage to crops: perceptions of agricultural and wildlife professionals in 1957 and 1987. Wildlife Society Bulletin 19:46-52.

Conover, M. R., W. C. Pitt, K. K. Kessler, T. J. DuBow, and W. A. Sanborn. 1995. Review of human injuries, illnesses, and economic losses caused by wildlife in the United States. Wildlife Society Bulletin 23:407-414.

Côté, S. D., T. P. Rooney, J. P. Tremblay, C. Dussault, and D. W. Waller. 2004. Ecological impacts of deer overabundance. Annual Review of Ecology, Evolution, and Systematics 34:113-147.

Craven, S. R., and S. E. Hygnstrom. 1994. Deer. Pages D25-D40 in S. E. Hygnstrom, R. M. Timm, and G. E. Larson, editors. Prevention and control of wildlife damage. University of Nebraska Cooperative Extension Service, Lincoln, USA.

D’Angelo, G. J., A. R. De Chicchis, D. A. Osborn, G. R. Gallagher, R. J. Warren, and K. V. Miller. 2007. Hearing range of white-tailed deer as determined by auditory brainstem response. Journal of Wildlife Management 71:1238-1242.

DeNicola, A. J., and S. C. Williams. 2008. Sharpshooting suburban whitetailed deer reduces deer-vehicle collisions. Human-Wildlife Conflicts 2:28-33.

DeVault, T. L., J. L. Belant, B. F. Blackwell, and T. W. Seamans. 2011. Interspecific variation in wildlife hazards to aircraft: implications for airport wildlife management. Wildlife Society Bulletin:in press.

DeVault, T. L., J. E. Kubel, D. J. Glista, and O. E. Rhodes, Jr. 2008. Mammalian hazards at small airports in Indiana: impact of perimeter fencing. Human-Wildlife Conflicts 2:240-247.

DeVault, T. L., J. E. Kubel, O. E. Rhodes, Jr., and R. A. Dolbeer. 2009. Habitat and bird communities at small airports in the Midwestern USA. Proceedings Wildlife Damage Management Conference 13:137-145. 
Dolbeer, R. A. 2009. Wildlife strike reporting, part 2-sources of data in voluntary system. U.S. Department of Transportation, Federal Aviation Administration Report DOT/FAA/AR-09/63, Washington, D.C., USA.

Dolbeer, R. A., M. J. Begier, and S. E. Wright. 2008. Animal ambush: the challenge of managing wildlife hazards at general aviation airports. Corporate Aviation Safety Seminar 53:1-12.

Dolbeer, R. A., and S. E. Wright. 2009. Safety management systems: how useful will the FAA National Wildlife Strike Database be? HumanWildlife Conflicts 3:167-178.

Dolbeer, R. A., S. E. Wright, and E. C. Cleary. 2000. Ranking the hazard level of wildlife species to aviation. Wildlife Society Bulletin 28:372-378.

Dolbeer, R. A., S. E. Wright, J. Weller, and M. J. Beiger. 2009. Wildlife strikes to civil aircraft in the United States, 1990-2008. U.S. Department of Transportation, Federal Aviation Administration, Office of Airport Safety and Standards, Serial Report no. 15, Washington, D.C., USA.

Federal Aviation Administration (FAA). 2004. Deer hazard to aircraft and deer fencing. U.S. Department of Transportation, Federal Aviation Administration, CertAlert 04-16, Washington, D.C., USA.

Federal Aviation Administration (FAA). 2010a. FAA summary data. FAA terminal area forecast summary report FY 2009-2030. http://www. faa.gov/data_research/aviation/taf_reports/media/TAF\%20Summary\% 20Report\%20FY\%202009\%20-\%202030.pdf. Accessed 23 Oct 2010.

Federal Aviation Administration (FAA). 2010b. FAA air traffic activity system. http://aspm.faa.gov/opsnet/sys/Airport.asp. Accessed 30 Nov 2010.

Federal Aviation Administration (FAA). 2010c. FAA airport data. FAA airport facilities data report. http://www.faa.gov/airports/airport_safety/ airportdata_5010/. Accessed 1 Nov 2010.

Gosner, R. A., R. R. Jensen, and S. E. Wolf. 2009. The spatial ecology of deer-vehicle collisions. Applied Geography 29:527-532.

Horsley, S. B., S. L. Stout, and D. S. DeCalesta. 2003. White-tailed deer impact on the vegetation dynamics of a northern hardwood forest. Ecological Applications 13:98-118.

Hussain, A., J. B. Armstrong, D. B. Brown, and J. Hogland. 2007. Land-use pattern, urbanization, and deer-vehicle collisions in Alabama. HumanWildlife Conflicts 1:89-96.

Ishmael, W. E., and O. J. Rongstad. 1984. Economics of an urban deerremoval program. Wildlife Society Bulletin 12:394-398.

Iverson, A. L., and L. R. Iverson. 1999. Spatial and temporal trends of deer harvest and deer-vehicle collisions in Ohio. Ohio Journal of Science 99:84-94.

Jones, J. M., and J. H. Witham. 1990. Post-translocation survival and movements of metropolitan white-tailed deer. Wildlife Society Bulletin 18:434-441.

Knight, T. M., H. Caswell, and S. Kalisz. 2009. Population growth rate of a common understory herb decreases non-linearly across a gradient of deer herbivory. Forest Ecology and Management 257:1095-1103.
Miller, B. F., R. W. DeYoung, T. A. Campbell, B. R. Laseter, W. M. Ford, and K. V. Miller. 2010. Fine-scale genetic and social structuring in central Appalachian white-tailed deer herd. Journal of Mammalogy 91:681-689.

Miller, K. V., L. I. Muller, and S. Demarais. 2003. White-tailed deer (Odocoileus virginianus). Pages 906-930 in G. A. Feldhamer, B. C. Thompson, and J. A. Chapman, editors. Mammals of North America: biology, management and conservation. Second edition. Johns Hopkins University Press, Baltimore, Maryland, USA.

O'Bryan, M. K., and D. R. McCullough. 1985. Survival of black-tailed deer following relocation in California. Journal of Wildlife Management 49: $115-119$.

Pauley, G. R., J. M. Peek, and P. Zager. 1993. Predicting white-tailed deer habitat use in northern Idaho. Journal of Wildlife Management 57:904913.

Rooney, T. P., S. L. Solheim, and D. M. Waller. 2002. Factors affecting the regeneration of northern white cedar in lowland forests of the upper Great Lakes region, USA. Forest Ecology and Management 163:119-130.

Seamans, T. W., and D. A. Helon. 2008. Evaluation of an electrified mat as a white-tailed deer (Odocoileus virginianus) barrier. International Journal of Pest Management 54:89-94.

Seamans, T. W., and K. C. VerCauteren. 2006. Evaluation of ElectroBraid ${ }^{\mathrm{TM}}$ fencing as a white-tailed deer barrier. Wildlife Society Bulletin 34:8-15.

Telford, S. R., III. 2002. Deer tick-transmitted zoonoses in the eastern United States. Pages 310-324 in A. A. Aguirre, R. S. Ostfeld, G. M. Tabor, C. House, and M. C. Pearl, editors. Conservation medicine: ecological health in practice. Oxford University Press, New York, New York, USA.

Tzilkowski, W. M., M. C. Brittingham, and M. J. Lovallo. 2002. Wildlife damage to corn in Pennsylvania: farmer and on-the-ground estimates. Journal of Wildlife Management 66:678-682.

VerCauteren, K. C., M. J. Lavelle, and S. Hygnstrom. 2006. Fences and deer-damage management: a review of designs and efficacy. Wildlife Society Bulletin 34:191-200.

VerCauteren, K. C., and M. J. Pipas. 2003. A review of color vision in whitetailed deer. Wildlife Society Bulletin 31:684-691.

VerCauteren, K. C., T. R. Van Deelen, M. J. Lavelle, and W. H. Hall. 2010. Assessment of abilities of white-tailed deer to jump fences. Journal of Wildlife Management 74:1378-1381.

Wright, S. E., R. A. Dolbeer, and A. J. Montoney. 1998. Deer on airports: an accident waiting to happen. Proceedings Vertebrate Pest Conference 18:90-95.

Yokoyama, S., and B. Radlwimmer. 1998. The "five sites" rule and the evolution of red and green color vision in mammals. Molecular Biology and Evolution 15:560-567.

Associate Editor: Nielsen. 